\title{
KORELASI DATA GEOLISTRIK DAN ELECTRICAL LOGGING UNTUK ANALISIS KETEBALAN LAPISAN BATUAN PIROKLASTIK DI DESA WATANG PULU, KECAMATAN SUPPA, KABUPATEN PINRANG
}

\author{
Syarifullah Bundang*, Busthan Azikin, Sultan \\ Departemen Teknik Geologi, Universitas Hasanuddin, Makassar, Indonesia. \\ *Corresponding author. Email: bundangsyarifullah@gmail.com
}

Manuscript received: 23 September 2020; Received in revised form: 13 October 2020; Accepted: 16 October 2020

\begin{abstract}
Abstrak
Penyebaran batuan gunungapi Parepare yang begitu luas di beberapa daerah termasuk Pinrang. Hasil overlay peta geologi dan lokasi penelitian, daerah tersebut tersusun dari Formasi Batuan Gunungapi Parepare (Tppv). Namun masih sangat kurang referensi atau penelitian tentang sebaran batuan gunungapi Parepare secara vertikal. Pengukuran geolistrik tahanan jenis (resistivitas) dan pengukuran electrical logging (log SP dan resistivitas) merupakan gabungan metode geofisika yang bisa digunakan untuk melihat secara detail kondisi penyebaran vertikal litologi batuan. Dengan melakukan korelasi data geolistrik dan electrical logging maka akan mempermudah untuk menginterpretasi ketebalan lapisan batuan piroklastik. Penelitian ini bertujuan untuk menganalisis litologi bawah permukaan dan menganalisis ketebalan lapisan batuan piroklastik Formasi Batuan Gunungapi Parepare menggunakan korelasi data geolistrik dan electrical logging. Metode yang digunakan adalah pengukuran geolistrik metode vertical electrical sounding (VES) konfigurasi Schlumberger sebanyak 1 lintasan dan electrical logging dengan kedalaman sumur $70 \mathrm{~m}$. Dari hasil pengukuran geolistrik diperoleh nilai resistivitas 193 $\Omega \mathrm{m}-927 \Omega \mathrm{m}$ ddengan kedalaman 55,1 $\mathrm{m}$ dan hasil pengukuran electrical logging short resistivitas yaitu $214 \Omega \mathrm{m}-495 \Omega \mathrm{m}$, nilai long resistivitas yaitu $281 \Omega \mathrm{m}-725 \Omega \mathrm{m}$ sedangkan nilai self potential (SP) terendah dan tertinggi yaitu $89 \mathrm{mV}$ dan $210 \mathrm{mV}$. Berdasarkan hasil korelasi data geolistrik dan electrical logging diinterpretasikan litologi pada lokasi penelitian terdapat 3 lapisan yaitu lanau pasiran (kedalaman $0-2.6 \mathrm{~m}$ ), lempung pasiran (kedalaman 2,6-7,8 m) dan breksi vulkanik (kedalaman 7,8 $-70 \mathrm{~m}$ ) dan ketebalan batuan piroklastik pada lokasi penelitian yang merupakan batuan breksi volkanik yaitu $62,2 \mathrm{~m}$.
\end{abstract}

Kata kunci: batuan piroklastik; geolistrik; electrical logging.

\begin{abstract}
Parepare volcanic rock is widely popular in several areas including Pinrang. The results of the geological map overlay and the research location, the area is composed of a Parepare Volcanic Rocks Formation (Tppv). However, there is still a lack of references or research on the vertical distribution of Parepare volcanic rocks. Geoelectric measurements of resistivity and electrical logging measurements (SP logs and resistivity) are a combination of geophysical methods that can be used to see in detail the conditions of rock lithology distribution. By correlating geoelectric data and electrical logging, it will be easier to interpret the thickness of the rock layers. This study aims to analyze the basic lithology and analyze the thickness of the pyroclastic rock layers of the Parepare Volcanic Rock Formation using geoelectric data and electrical logging. The method used is the geoelectric measurement method, the vertical electrical sounding method (VES), Schlumberger analysis of 1 pass and electric logging with a
\end{abstract}


well depth of $70 \mathrm{~m}$ From the results of geoelectric measurements, the resistivity value is $193 \Omega \mathrm{m}-927$ $\Omega \mathrm{m}$ with a depth of $55.1 \mathrm{~m}$ and the measurement results of short resistivity measurements are $214 \Omega \mathrm{m}$ $-495 \Omega \mathrm{m}$, for long resistivity is $281 \Omega \mathrm{m}-725 \Omega \mathrm{m}$ while the the lowest and the highest self potential (SP) value are $89 \mathrm{mV}$ and $210 \mathrm{mV}$. Based on the results of geoelectric data and electrical logging, the lithology interpreted at the research location there were 3 layers, namely sandy silt $(0-2.6 \mathrm{~m}$ depth $)$, sandy clay (depth $2.6-7.8 \mathrm{~m}$ ) and volcanic breccia (depth $7.8-70 \mathrm{~m}$ ) and the thickness of pyroclastic rocks at research location which is a volcanic breccia rock that is $62.2 \mathrm{~m}$.

Keywords: pyroclastic rocks; geoelectric; electrical logging.

\section{Pendahuluan}

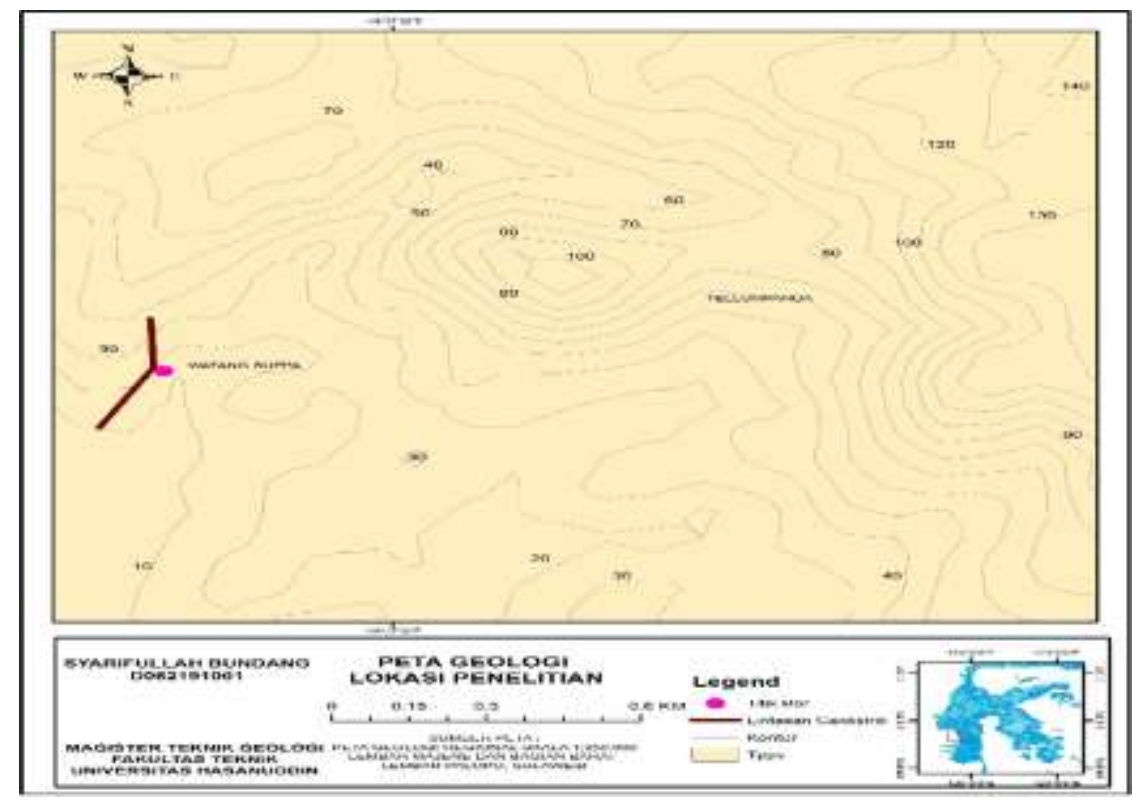

Gambar 1. Peta geologi lokasi penelitian (dimodifikasi setelah Djuri dkk., 1998).

Menurut Yuwono (1990), batuan vulkanik Parepare adalah sisa-sisa gunung stratovolcano yang terdiri aliran lava dan breksi piroklastik berumur akhir Miosen. Batuan Gunungapi Parepare yang terdapat di Parepare (piroklastik) maupun yang ada di Pangkajene Sidrap (aliran lava ignimbrite), termasuk dalam kerabat batuan shoshonitic.

Penyebaran batuan vulkanik Parepare tersebar di beberapa lokasi seperti, menutupi Kota Parepare, bagian Utara Kabupaten Pinrang, bagian Timur Kabupaten Sidrap dan bagian Selatan Kabupaten Barru (Kaharuddin, 2009). Namun masih sangat kurang referensi tentang penyebaran batuan vulkanik Parepare secara vertikal, maka dari itu sangat penting dilakukan penelitian untuk mengetahui litologi bawah permukaan dari formasi tersebut.

Pengukuran geolistrik tahanan jenis (resistivitas) dan pengukuran electrical logging (log SP dan resistivitas) merupakan gabungan metode geofisika yang bisa digunakan untuk melihat secara detail kondisi penyebaran vertikal litologi batuan.

Dengan melakukan korelasi data geolistrik dan electrical logging maka akan mempermudah untuk menginterpretasi ketebalan lapisan batuan piroklastik di Desa Watangpulu, Kecamatan Suppa, Kabupaten Pinrang.

Tujuan dari penilitian ini yaitu untuk menganalisis litologi bawah permukaan dan ketebalan lapisan batuan piroklastik 
pada Formasi Batuan Gunungapi Parepare menggunakan korelasi data geolistrik dan electrical logging

\section{Geologi Daerah Penelitian}

Berdasarkan peta geologi regional, daerah penelitian masuk kedalam peta geologi lembar Majene dan Bagian Barat Lembar Palopo (Djuri dkk., 1998).

Hasil overlay peta geologi dan lokasi penelitian (Gambar 1), daerah tersebut tersusun dari formasi, Batuan Gunungapi Parepare (Tppv), yang terdiri dari Breksi gunungapi dengan fragmen trakit dan andesit; batuapung, batupasir tufaan, konglomerat dan breksi tufaan; diterobos oleh, retas-retas trakit- andesit (Djuri dkk., 1998).

\section{Geolistrik Tahanan Jenis (Resistivitas)}

Metode geolistrik adalah metode yang menggunakan arus listrik untuk mengidentifikasi bawah permukaan dengan beda potensial yang dihasilkan. Metode tersebut dapat digunakan untuk mengukur potensial, arus dan medan elektromagnetik yang alami atau buatan di dalam bumi. Pengukuran bisa dilakukan dalam berbagai variasi sesuai dengan kebutuhan (Telford dkk., 1990).

Beberapa jenis konfigurasi yang sering digunakan dan faktor geometrinya (Loke, 2001)
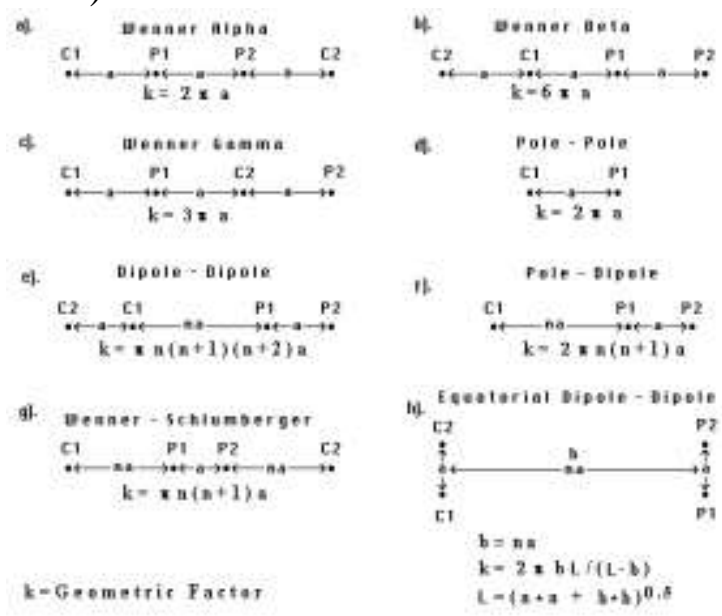

Gambar 2. Susunan konfigurasi dan faktor geometri (Loke, 2001).
Persamaan yang digunakan untuk menghitung resistivitas semu adalah:

$$
\rho_{a}=K \frac{\Delta V}{I}
$$

Hasil survei resistivitas memberikan gambaran distribusi nilai resistivitas bawah permukaan. Untuk menginterpretasi gambaran resistivitas bawah permukaan menjadi sebuah gambaran geologi maka diperlukan pengetahuan untuk membedakan tipe dari material bawah permukaan dan kenampakan geologinya berdasarkan nilai resistivitasnya sangat dibutuhkan (Telford dkk., 1990).

Beberapa hal yang mempengaruhi nilai resistivitas batuan, derajat kekompakan dan besarnya persentase kandungan fluida yang mengisi batuan. Beberapa jenis batuan biasanya memiliki nilai resistivitas yang overlap. Hal tersebut disebabkan karena resistivitas dari batuan dipengaruhi oleh beberapa faktor, antara lain kandungan lempung, keterdapatan air tanah, jenis dan karakteristik fisik batuan, mineralogi batuan. Nilai resistivitas batuan dapat dilihat pada Tabel 1.

Tabel 1. Nilai- nilai resistivitas batuan (Sedana dkk., 2015).

\begin{tabular}{cll}
\hline No. & Jenis Batuan & Resistivitas $(\mathbf{\Omega m})$ \\
\hline 1 & Lempung & $1-100$ \\
2 & Lanau & $10-200$ \\
3 & Batu Lumpur & $3-70$ \\
4 & Kuarsa & $10-2 \times 10^{8}$ \\
5 & Batu Pasir & $1-1.000$ \\
6 & Gamping & $100-500$ \\
7 & Lava & $100-5 \times 10^{4}$ \\
8 & Air Tanah & $0.5-300$ \\
9 & Breksi & $75-200$ \\
10 & Andesit & $100-200$ \\
11 & Tufa & $20-100$ \\
12 & Konglomerat & 2 \\
\hline
\end{tabular}

\section{Electrical Logging}

Metode pengukuran electrical logging merupakan salah satu metode geofisika yang digunakan untuk melihat penyebaran 
lapisan bawah permukaan secara vertikal (Umar dan Setiawan, 2017). Prinsip dasar metode tersebut adalah mengukur parameter sifat-sifat fisik dari suatu batuan pada setiap kedalaman secara kontinyu dari sumur pemboran. Adapun sifat-sifat fisik yang dapat diukur adalah potensial listrik batuan, tahanan jenis batuan, radioaktivitas, kecepatan rambat gelombang elastis, kerapatan formasi (densitas), dan kemiringan lapisan batuan, serta kekompakan formasi yang kesemuanya tercermin dari lubang bor.

\section{Batuan Gunungapi Parepare}

Menurut Williams dkk. (1982), batuan piroklastik adalah batuan volkanik klastik yang dihasilkan dari proses letusan gunungapi. Material penyusun tersebut terendapkan dan terkonsolidasi sebelum mengalami transportasi oleh air atau es.

Batuan vulkanik Parepare berada di atas himpunan batuan sedimen dan volkanosedimenter dari Formasi Camba yang berumur Miosen Bawah - Miosen Atas. Umur relatif vulkanik Parepare yaitu setelah Miosen Atas. Umur dari tufa dan trakit yaitu 4,95 Ma dan 4,25 Ma (Sukamto, 1982) sedangkan menurut Yuwono (1994) hasil analisis K/Ar dan menunjukan kisaran umur absolut 6,50 \pm 0,32 Ma sampai dengan 4,57 $\pm 0,23 \mathrm{Ma}$ atau Mio Pliosen. Batuan vulkanik Parepare merupakan produk sisa gunungapi strato-volcano yang terdiri dari tufa berukuran halus - lapilli dan breksi vulkanik dengan fragmen trakitik dan andesitik.

Menurut Irfan dkk. (2014), berdasarkan perbedaan pembentukan batuan dan komposisi fragmen, batuan vulkanik Parepare dapat dikelompokkan dalam tiga litofasies antara lain Lava, Proklastik dan Vulkaniklastik. Fasies lava dan piroklastik berasosiasi dengan proses vulkanik primer, sedangkan vulkaniklastik terkait dengan proses sekunder.

\section{Metode Penelitian}

Penelitian ini dilakukan di Desa Watang Pulu, Kecamatan Suppa, Kabupaten Pinrang, Provinsi Sulawesi Selatan (Gambar 3). Secara astronomis terletak pada koordinat $119^{\circ} 37^{\prime} 14,60^{\prime \prime}$ BT dan $03^{\circ}$ 56' 33,52" LS - $119^{\circ} 37^{\prime} 20,27^{\prime \prime}$ BT dan $03^{\circ}$ 56' 33,63" LS. Akses menuju lokasi penelitian dapat dicapai baik dengan kendaraan roda 2 ataupun roda 4 dengan jarak tempuh $\pm 170 \mathrm{~km}$ dari Kota Makassar ke arah Utara.

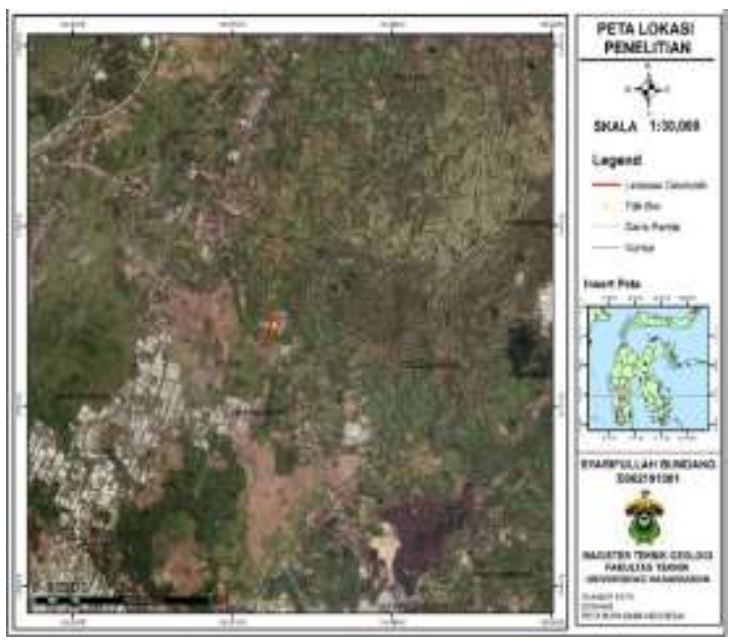

Gambar 3. Peta lokasi penelitian

Penelitian ini menggunakan pendekatan yang mengkombinasikan antara penelitian kuantitatif dan kualitatif. Metode yang diterapkan yaitu dengan memadukan hasilhasil kajian pustaka, penelitian terdahulu dan data lapangan, yang keseluruhannya dikaji, dianalisis, untuk mendefinisikan kesimpulan tentang kondisi bawah permukaan formasi batuan gunungapi Parepare di Desa Watangpulu, Kecamatan Suppa, Kabupaten Pinrang.

Metode pengumpulan data pada penelitian ini yaitu data primer dan sekunder. Data primer diperoleh dengan melakukan observasi lapangan berupa pengamatan secara fisik singkapan batuan, pengukuran geolistrik resistivitas metode Vertical Electrical Sounding (VES) dengan konfigurasi Schlumberger, sebanyak 1 lintasan dengan panjang 400 dan pengukuran Electrical Logging (Log SP dan Resistivitas) pada sumur dengan 
kedalaman $70 \mathrm{~m}$. Sedangkan untuk data sekunder diperoleh dengan melakukan dengan pengumpulan data atau referensi tentang geologi daerah penelitian.

Metode analisis data pada penelitian ini untuk singkapan batuan dilakukan analisis secara megaskopis untuk menentukan jenis batuan singkapan, analisis data resistivitas dari pengukuran geolistrik Electrical Sounding (VES) menggunakan Software IP2WIN. Analisis data dari hasil pengukuran Electrical Logging (Log SP dan Resistivitas) menggunakan Software Microsoft Excel untuk menentukan jenis lapisan bawah permukaan dan ketebalan lapisan batuan piroklastik.

\section{Hasil dan Pembahasan}

\section{Analisis Singkapan Batuan}

Pada penelitian ini dilakukan analisis pada singkapan batuan di lokasi penelitian yang akan menjadi salah satu acuan untuk melakukan interpretasi bawah permukaan dari pengukuran geolistrik dan electrical logging. Setelah dilakukan pengamatan secara langsung dan deskripsi megaskopis pada singkapan batuan (Gambar 4) di lapangan, satuan batuan yang dijumpai di daerah penelitian, memiliki ciri fisik, warna segar abu-abu, warna lapuk cokelat, tekstur piroklastik kasar, fragmen berupa andesit dan trakit. Bentuk fragmen sub-rounded dengan ukuran $(1 \mathrm{~cm}-10 \mathrm{~cm})$, matriks berukuran $0.5 \mathrm{~mm}-1 \mathrm{~mm}$ tuf kasar dan sortasi yang buruk. Berdasarkan klasifikasi WTG dan ciri fisik tersebut dinamakan batuan breksi vulkanik.
Hasil tersebut memperlihatkan adanya keterkaitan dengan penelitian yang dilakukan oleh Irfan dkk. (2014) pada formasi batuan gunungapi Parepare di daerah Lumpue. Menurut Irfan dkk. (2014) Singkapan breksi vulkanik memiliki ciri fisik, warna abu - abu kehitaman dan warna lapuk coklat kehitaman, tekstur piroklastik kasar, fragmen berupa trakit dan andesit. Fragmen berbentuk angular subrounded dan berukuran $1-56 \mathrm{~cm}$. Komponen matriks berupa tufa lapilli. Ukuran fragmen breksi vulkanik yang dijumpai pada fasies ini menunjukkan sortasi buruk karena memiliki ukuran butir yang tidak seragam. Hasil yang relefan juga dari penelitian yang dilakukan oleh Amsah (2016) pada formasi batuan gunungapi Parepare, menurut Amsah (2016) pada kenampakan singkapan lapangan litologi ini memiliki ciri sifat fisik, berwarna segar abu-abu, warna lapuk kecoklatan, tekstur piroklastik kasar yang fragmen tersebut berasal dari batuan beku berupa basalt dengan ukuran fragmen 2 $40 \mathrm{~cm}$, bentuk fragmen menyudut tanggung, sortasi buruk kerena memiliki ukuran butir yang tidak seragam, kemas terbuka karena hubungan antar butirnya tidak saling menyentuh, matriks berupa tufa kasar, dan semen berupa gelas vulkanik, pada umumnya memiliki struktur tidak berlapis. Nama batuan berdasarkan WTG adalah breksi vulkanik. Hasil pengamatan mikroskopik menunjukan warna absorbsi coklat, warna interferensi coklat kehitaman, tekstur vitrofiri, komposisi material kristal $(35 \%)$, gelas $(15 \%)$, dan rock fragment $(50 \%)$. 


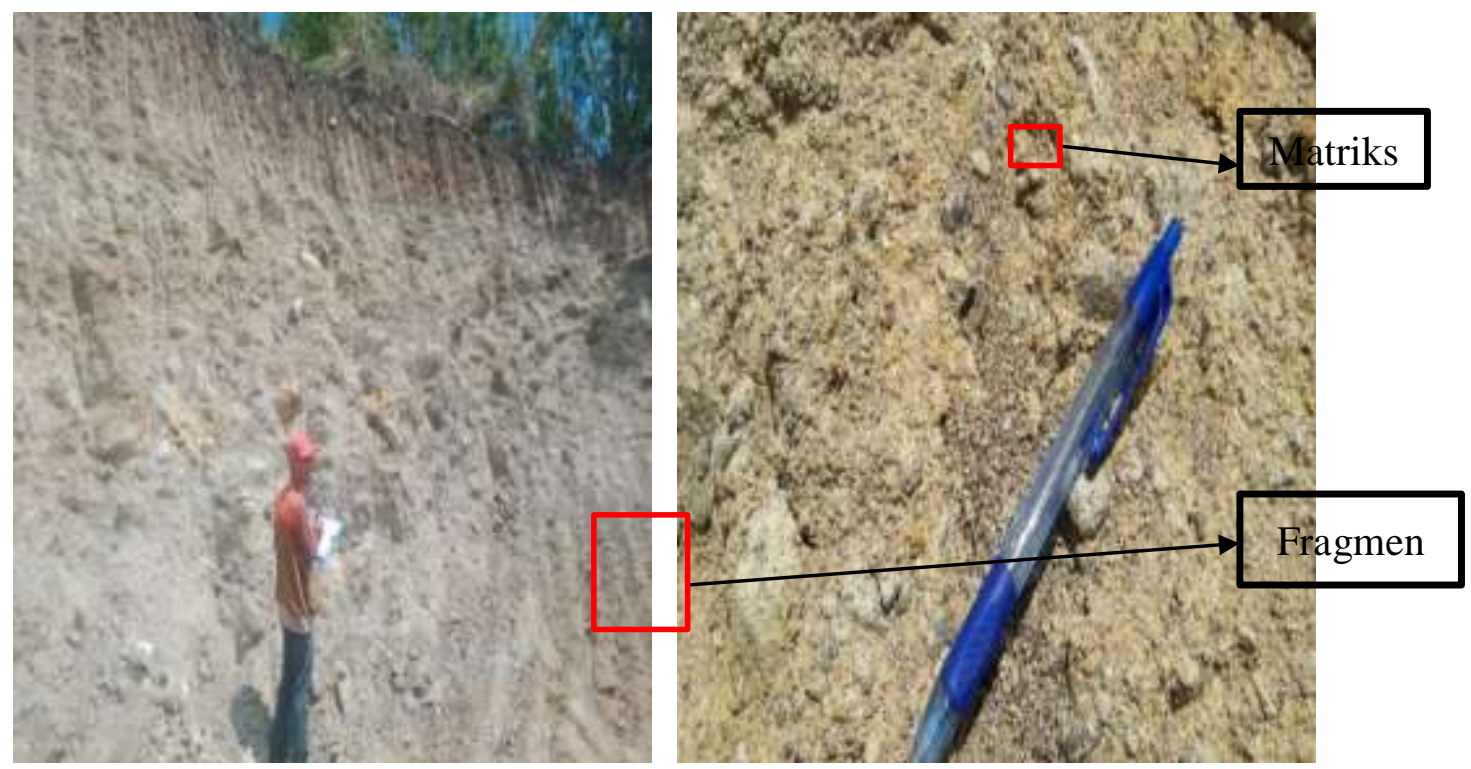

Gambar 4. Singkapan batuan pada lokasi penelitian.

\section{Analisis Geolistrik Resistivitas}

Hasil inversi kurva VES dapat dilihat pada (Gambar 5). Interpretasi hasil pengukuran geolistrik dilakukan berdasarkan data nilai resistivitas, singkapan batuan, referensi geologi regional, informasi masyarakat dan literatur tentang geolistrik. Berdasarkan hasil pengukuran diperoleh kurva VES (Gambar 5b) dengan nilai resistivitas terendah $193 \Omega \mathrm{m}$ dan nilai resistivitas terbesar yaitu $927 \Omega \mathrm{m}$ dan penetrasi kedalaman 55,1 m. Berdasarkan kurva VES pada Gambar 5 diinterpretasikan terdapat 3 lapisan (Tabel 2), yaitu:

1. Lapisan 1, nilai resistivitas $193-290$ $\Omega \mathrm{m}$ dengan ketebalan $2,73 \mathrm{~m}$ pada kedalaman $0-2,73$ m diinterpretasikan sebagai lapisan lanau berpasir (top soil). Berdasarkan informasi yang didapatkan pada saat survei lokasi baik itu singkapan maupun informasi dari masyarakat, daerah lintasan ini merupakan daerah penimbunan.

2. Lapisan 2 , nilai resistivitas $76,8 \Omega \mathrm{m}$ dengan ketebalan lapisan $5,93 \mathrm{~m}$ pada kedalaman $2,73-8.66 \mathrm{~m}$ diinterpretasikan sebagai lempung. Keberadaan lempung pada daerah tersebut diperkiran hasil dari pelapukan batuan breksi vulkanik.

3. Lapisan 3, nilai resistivitas $460 \Omega \mathrm{m}-$ $927 \Omega \mathrm{m}$ dengan ketebalan lapisan 40,4 m pada kedalaman 8,66 - $55.1 \mathrm{~m}$ diinterpretasikan sebagai batuan breksi vulkanik. Lapisan ini memiliki ketebalan yang sangat tebal, dimana pada lapisan tersebut memiliki nilai resistivitas yang beragam disebabkan oleh tingkat pelapukan yang berbeda dan keberadaan air tanah serta fragmen pada batuan tersebut.

Tabel 2. Litologi batuan berdasarkan data pengukuran geolistrik resistivitas.

\begin{tabular}{ccccc}
\hline \multirow{2}{*}{ No } & Litologi & $\begin{array}{c}\text { Resistivitas } \\
(\mathbf{\Omega m})\end{array}$ & $\begin{array}{c}\text { Ketebalan } \\
(\mathbf{m})\end{array}$ & $\begin{array}{c}\text { Kedalaman } \\
(\mathbf{m})\end{array}$ \\
\hline 1 & Lanau Pasiran & $193-290$ & 2,73 & $0-2,73$ \\
2 & Lempung pasiran (Lapukan & 76,8 & 59,3 & $2,73-8,66$ \\
& breksi) & $460-927$ & 40,4 & $8,66-55,1$ \\
\hline
\end{tabular}




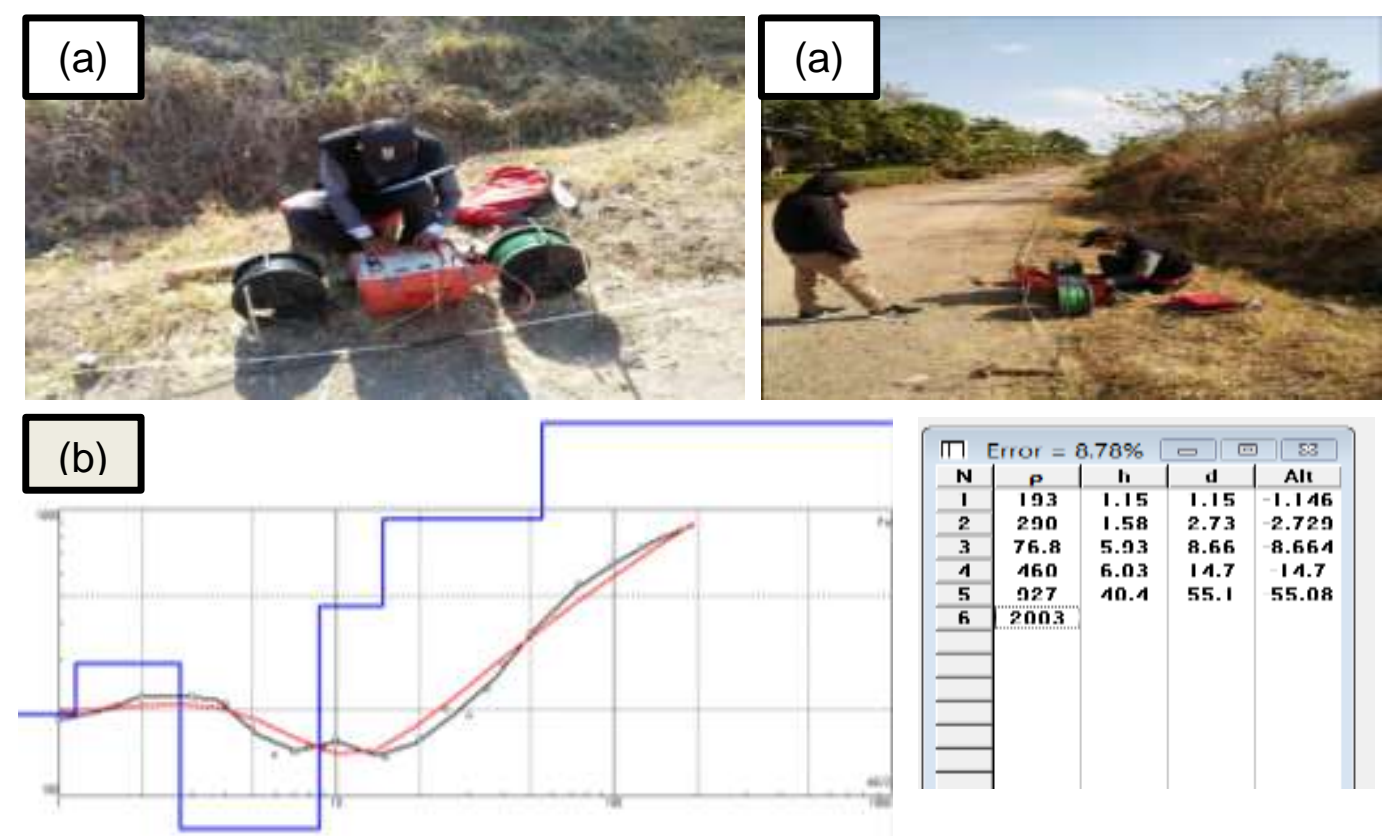

Gambar 5. (a) proses akuisisi data dan (b) kurva VES hasil inversi.

Berdasarkan hasil tersebut ketebalan lapisan batuan piroklastik yaitu 40,4 m pada kedalaman 8,66 - 55,1 m dengan nilai resistivitas $460-927 \Omega \mathrm{m}$.

\section{Analisis Data Electrical Logging}

Pengukuran electrical logging dilakukan di titik pemboran pada koordinat $119^{\circ} 37^{\prime}$ 14,96" BT dan 03 ${ }^{\circ}$ 56' 33,28" LS. Pengukuran tersebut dilakukan sampai kedalaman $70 \mathrm{~m}$, pengukuran atau injeksi arus dilakukan setiap 1 meter. Data yang diperoleh dari pengukuran tersebut berupa nilai resistivitas, SP dan kedalaman. Data tersebut kemudian diolah menggunakan software Microsoft Excell.

Interpretasi hasil pengukuran electrical logging dilakukan berdasarkan data nilai resistivitas dan SP, singkapan batuan dan referensi geologi regional. Berdasarkan hasil pengukuran diperoleh model kurva electrical log (resistivitas dan SP) (Gambar 6) dengan nilai resistivitas terendah dan tertinggi pada short resistivitas yaitu $214-495 \Omega \mathrm{m}$, untuk long resistivitas yaitu $281-725 \Omega$ m sedangkan nilai self potential (SP) terendah dan tertinggi yaitu $89 \mathrm{mV}$ dan $210 \mathrm{mV}$. Berikut ini interpretasikan dari hasil pengukuran serta pengolahan data electrical logging:

1. Lapisan pada kedalaman $0-2,6 \mathrm{~m}$ mempunyai nilai potensial $89-92 \mathrm{mV}$, nilai short resistivity 232 - $236 \Omega \mathrm{m}$ dan nilai long resistivity antara $281-288$ $\Omega \mathrm{m}$, lapisan tersebut diinterpretasikan sebagai lanau pasiran.

2. Lapisan pada kedalaman $2,6-7,8 \mathrm{~m}$ dengan nilai potensial $102-106 \mathrm{mV}$, nilai short resistivity $214-218 \Omega \mathrm{m}$ dan nilai long resistivity antara $312-316$ $\Omega \mathrm{m}$ diinterpretasikan sebagai lempung pasiran yang merupakan produk pelapukan batuan breksi vulkanik. 


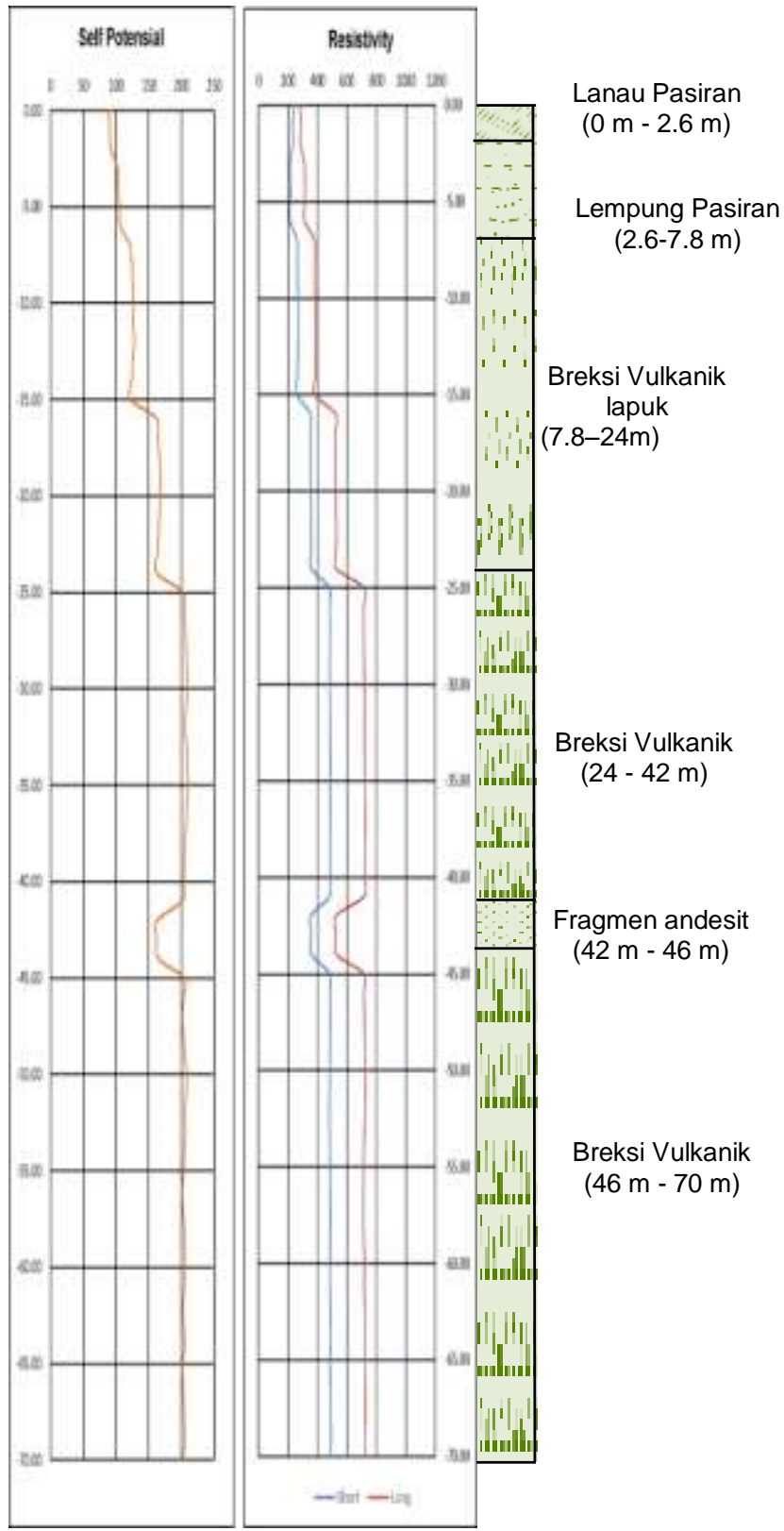

Gambar 6. Kurva hasil pengukuran electrical logging (resistivitas dan SP).

3. Lapisan pada kedalaman 7,8 - $24 \mathrm{~m}$ dengan nilai potensial $121-168 \mathrm{mV}$, nilai short resistivity $262-359 \Omega \mathrm{m}$ dan nilai long resistivity $380-529 \Omega \mathrm{m}$. Lapisan tersebut diinterpretasikan sebagai batuan breksi vulkanik yang mengalami pelapukan. Kondisi tersebut dipengaruhi oleh keberadaan air tanah pada lapisan tersebut.

4. Lapisan pada kedalaman $24-42 \mathrm{~m}$ dengan nilai potensial $201-209 \mathrm{mV}$, nilai short resistivity $480-489 \Omega \mathrm{m}$ dan nilai long resistivity $711-724 \Omega \mathrm{m}$ lapisan tersebut diinterpretasikan sebagai batuan breksi vulkanik yang segar.

5. Lapisan pada kedalaman $42-44 \mathrm{~m}$ memiliki nilai potensial $162-165 \mathrm{mV}$, nilai short resistivity $356-360 \Omega \mathrm{m}$ dan nilai long resistivity antara 525 - 528 $\Omega \mathrm{m}$ berdasarkan korelasi dengan hasil pemboran lapisan tersebut diinterpretasi sebagai fragmen dari batuan breksi vulkanik yaitu andesit yang berukuran bongkah.

6. Lapisan pada kedalaman $44-70 \mathrm{~m}$ dengan nilai potensial $201-208 \mathrm{mV}$, nilai short resistivity antara $480-495$ $\Omega \mathrm{m}$ dan nilai long resistivity antara 711 
- $725 \Omega \mathrm{m}$, berdasarkan nilai dan resistivitas lapisan ini memiliki nilai yang hampir sama dengan lapisan pada kedalaman $24-42 \mathrm{~m}$ sehingga lapisan ini diinterpretasikan sama dengan lapisan pada kedalaman $24-42$ m yaitu batuan breksi vulkanik yang segar.
Berdasarkan hasil interpretasi pada pengukuran electrical logging (resistivitas dan SP), maka dapat disimpulkan bahwa litologi lokasi tersebut terdiri dari tiga lapisan (Tabel 3). Berdasarkan hasil tersebut ketebalan lapisan batuan piroklastik yaitu $62,2 \mathrm{~m}$ pada kedalaman $7,8-70 \mathrm{~m}$ dengan nilai resistivitas $262-$ $495 \Omega \mathrm{m}$.

Tabel 3. Litologi batuan berdasarkan data pengukuran electrical logging

\begin{tabular}{ccccccc} 
No & Litologi & $\begin{array}{c}\text { Potensial } \\
(\mathbf{m V})\end{array}$ & \multicolumn{2}{c}{ Resistivitas $(\Omega \mathrm{m})$} & \multirow{2}{*}{$\begin{array}{c}\text { Ketebalan } \\
(\mathbf{m})\end{array}$} & $\begin{array}{c}\text { Kedalaman } \\
(\mathbf{m})\end{array}$ \\
\hline 1 & $\begin{array}{c}\text { Lanau } \\
\text { Pasiran }\end{array}$ & $89-92$ & $232-236$ & $281-288$ & 2.6 & $0-2.6$ \\
2 & $\begin{array}{c}\text { Lempung } \\
\text { pasiran }\end{array}$ & $102-106$ & $214-218$ & $312-316$ & 5.2 & $2.6-7.8$ \\
3 & $\begin{array}{c}\text { Breksi } \\
\text { vulkanik }\end{array}$ & $121-209$ & $262-495$ & $380-724$ & 62.2 & $7.8-70$ \\
\hline
\end{tabular}

Korelasi Data Geolistrik dan Electrical Logging

Perbandingan data geolistrik dan electrical logging menunjukan adanya perbedaan pada nilai resistivitas, namun perbedaan tersebut tidak begitu signifikan. Hasil pengukuran geolistrik menunjukan nilai resistivitas yang lebih besar pada litologi yang diinterpretasi sebagai breksi vulkanik, hal tersebut disebabkan oleh pengaruh air tanah, dimana pada saat dilakukan pengukuran electrical logging terjadi kontak langsung antara elektroda dan air tanah di dalam sumur yang menyebabkan nilai resistivitas akan menurun. Berbeda dengan pengukuran geolistrik, elektroda hanya ditempatkan di permukaan sehingga terjadi reduksi nilai arus maupun potensial akibat dari faktor kedalaman. Meskipun terdapat perbedaan nilai resistivitas dari kedua metode tersebut tetapi dalam hal interpretasi litologi masih menunjukan kesamaan baik itu jenis lapisan, kedalaman dan ketebalan.

Interpretasi dari hasil pengukuran geolistrik dan electrical logging menunjukan nilai resistivitas yang relatif tinggi, hal tersebut dipengaruhi oleh keberadaan mineral silika $\left(\mathrm{SiO}_{2}\right)$ pada batuan. Menurut Yuwono (1990) dari hasil studi petrografi, mineralogi dan kimia batuan menunjukan bahwa batuan vulkanik Parepare memiliki kandungan silika yang sangat tinggi $\left(\mathrm{SiO}_{2}>\right.$ $58 \%)$.

\section{Kesimpulan}

Hasil analisis korelasi data geolistrik dan electrical logging dapat disimpulkan sebagai berikut:

1. Litologi pada lokasi penelitian terdiri dari lanau pasiran (kedalaman $0-2,6$ m), lempung pasiran (kedalaman 2,6 $7,8 \mathrm{~m}$ ) dan breksi vulkanik (kedalaman $7,8-70 \mathrm{~m})$.

2. Ketebalan batuan piroklastik pada lokasi penelitian yang merupakan batuan breksi volkanik yaitu 62,2 m.

\section{Ucapan Terima Kasih}

Ucapan terima kasih kami persembahkan kepada seluruh elemen yang telah membantu dan berpartisipasi sehingga penelitian ini bisa terlaksana, terutama 
kepada para dosen Teknik Geologi Universitas Hasanuddin.

\section{Daftar Pustaka}

Amsah, L.M.Y. 2016. Investigasi Bawah Permukaan Untuk Rekonstruksi Batuan Gunungapi Parepare di Daerah Datae Berdasarkan Nilai Resistivitas. Tesis, Universitas Hasanuddin.

Djuri, Sudjatmiko, Bachri, S. dan Sukido. 1998. Geologi Lembar Majene dan Bagian Barat Lembar Palopo Edisi Kedua. Pusat Penelitian dan Pengembangan Geologi Direktorat Jenderal Pertambangan Umum Departemen Pertambangan dan Energi: Bandung.

Irfan, U.R., Kaharuddin, Budiman dan Umar, H. 2014. Analisis Litofasies Batuan Vulkanik Parepare di Daerah Lumpue Sulawesi Selatan. di: The $43^{\text {st }}$ IAGI Annual Convention and Exhebition, September 2014, Jakarta. Proceedings PIT IAGI.

Kaharuddin. 2009. Studi Litofasies Batuan Gunungapi Parepare. Prosiding Hasil Penelitian Fakultas Teknik. Fakultas Teknik UNHAS, Makassar.

Loke, M. H. 2001. Tutorial: 2-D and 3-D Electrical Imaging Surveys.

Sedana, D., As'ari dan Tanauma, A. 2015. Pemetaan Akuifer Air tanah di Jalan Ringroad, Kelurahan Malendeng dengan Menggunakan Metode Geolistrik Tahanan Jenis. Jurnal Ilmiah Sains. 15 (2), pp.33-37.

Sukamto R. 1982. Geologi Lembar Pangkajene dan Watampone Bagian Barat Sulawes. Pusat Penelitian dan Pengembangan Geologi, Direktorat Jendral Pertambangan Umum dan Energi: Bandung.

Telford, W.M., Geldart, L.P. dan Sheriff, R.E. 1990. Applied Geophysics Second Edition. Cambridge University Press: Cambridge.

Umar E.P. dan Setiawan M.R.A. 2017. Pengukuran Electrical Logging pada
Pemboran Air Tanah Dalam di Daerah Pacciro Kecamatan Balusu Kabupaten Barru. Jurnal Geomine. vol. 5 (2): 90-93.

Williams, H., Turner, F.J. and Gilbert, C.M. 1982. Petrography; An Introduction The Study of Rocks In Thin Sections. W.H. Freeman Company: New York.

Yuwono, Y.S. 1990. Produk Volkanik Parepare (Sulawesi Selatan). di: PIT XIX IAGI, 11-13 Desember 1990, Bandung: Proc.PIT IAGI. 